Comment

\title{
Comment on Ryffel, G.U. I Have a Dream: Organic Movements Include Gene Manipulation to Improve Sustainable Farming. Sustainability 2017, 9, 392
}

\author{
Markus Arbenz * and David Gould \\ IFOAM-Organics International, Charles-de-Gaulle Strasse 5, 53113 Bonn, Germany; d.gould@ifoam.bio \\ * Correspondence: m.arbenz@ifoam.bio; Tel.: +49-228-92650-10; Fax: +49-228-92650-99 \\ Academic Editor: Marc A. Rosen \\ Received: 5 May 2017; Accepted: 5 May 2017; Published: 9 May 2017
}

To the Editor:

In the recent editorial "I Have a Dream: Organic Movements Include Gene Manipulation to Improve Sustainable Farming" [1], the author, Gerhart Ryffel, comments on the various papers published for the Special Issue in this journal on "Organic Farming and Gene Manipulation". Ryffel tries to find a way of integrating the organic and biotech world and bases much of his rationale, position, opinions, and conclusions of his paper on what appears to us to be a misinterpretation and misrepresentation of IFOAM-Organics International's clearly stated and published position on the topic of genetic engineering, new breeding techniques, and modern biotechnology, which he cited by [2] (old GMO definition) and [3] (new draft version for consultation of 2016 see Annex I).

IFOAM-Organics International is the world umbrella organisation of organic agricultural movements and the full definition as published in [3,4] is:

"Genetic engineering (GE) - A set of techniques from molecular biology (such as recombinant DNA and RNA) by which the genetic material of plants, animals, micro-organisms, cells and other biological units are altered in ways or with results that could not be obtained by methods of natural mating and reproduction or natural recombination. Techniques of genetic modification include, but are not limited to: recombinant DNA and/or RNA techniques, cell fusion, micro and macro injection, encapsulation, gene deletion and doubling. In addition, methods such as gene targeting and genome editing are classified as genetic engineering procedures. These depend on homologous recombination and non-homologous end joining, and employ engineered nucleases such as meganucleases, zinc finger nucleases (ZFNs), transcription activator-like effector nucleases (TALENs), and CRISPRs. Genetically engineered organisms do not include organisms resulting from techniques such as conjugation, transduction, natural hybridization, and marker assisted breeding."

IFOAM-Organics International's position is quite opposite to that which the author concludes. By simply citing only part (i.e., the first sentence) of our older definitions on Genetic Engineering and on Genetically Modified Organisms, the paper overlooks the 'process and product based approach' as discussed in [4] that clearly excludes the manipulation of any biological entity that is "altered in ways or with results ..." and thus enables his conclusion that the "IFOAM position paper does not exclude GM per se". The paper is also missing the more relevant reference of the final version accepted by IFOAM-Organics International members and published online on 30 November 2016 as the Position on Genetic Engineering and Genetically Modified Organisms [5]. In this context, it is important to stress that organic producers are certified based on their agricultural process. Thus, the organic sector's values are not product based. Breeding is considered as part of the process and therefore not just the variety characteristics as such but also the methods of breeding have to comply with the values of the organic sector [4]. 
We fully respect that the author does not share the same opinion and values; however, we also expect that IFOAM-Organics International's position paper is scientifically correctly cited and our position accurately represented in order to avoid any confusion and misleading amongst scientists, farmers, consumers and our members.

\section{References}

1. Ryffel, G.U. I Have a Dream: Organic Movements Include Gene Manipulation to Improve Sustainable Farming. Sustainability 2017, 9, 392. [CrossRef]

2. IFOAM. The IFOAM Norms for Organic Production and Processing. Version 2014. Available online: http://www.ifoam.bio/sites/default/files/ifoam_norms_july_2014_t.pdf (accessed on 8 May 2017).

3. IFOAM. IFOAM-Organics International Position on Genetic Engineering and Genetically Modified Organisms. Available online: http://www.ifoam.bio/en/news/2016/02/26/public-consultation-positionifoam-organics-international-genetic-engineering-and (accessed on 26 March 2017).

4. Nuijten, E.; Messmer, M.M.; Lammerts van Bueren, E.T. Concepts and Strategies of Organic Plant Breeding in Light of Novel Breeding Techniques. Sustainability 2017, 9, 18. [CrossRef]

5. IFOAM. IFOAM - Organics International Position paper on Genetic Engineering and Genetically Modified Organisms. 2016. Available online: http://www.ifoam.bio/sites/default/files/position_genetic_engineering_ and_gmos.pdf (accessed on 8 May 2017).

(C) 2017 by the authors. Licensee MDPI, Basel, Switzerland. This article is an open access article distributed under the terms and conditions of the Creative Commons Attribution (CC BY) license (http:// creativecommons.org/licenses/by/4.0/). 